\title{
Measuring public opinion and acceptability of prevention policies: an integrative review and narrative synthesis of methods
}

\author{
Eloise Howse ${ }^{1,2^{*}} \mathbb{D}$, Katherine Cullerton ${ }^{1,3}$, Anne Grunseit ${ }^{1,2}$, Erika Bohn-Goldbaum ${ }^{1,2}$, Adrian Bauman ${ }^{1,2}$ and \\ Becky Freeman ${ }^{2}$
}

\begin{abstract}
Acceptability of and public support for prevention are an important part of facilitating policy implementation. This review aims to identify, summarize and synthesize the methods and study designs used to measure and understand public opinion, community attitudes and acceptability of strategies to prevent chronic noncommunicable disease (NCDs) in order to allow for examination of imbalances in methodological approaches and gaps in content areas. We searched four scientific databases (CINAHL, Embase, Ovid/MEDLINE and Scopus) for peer-reviewed, English-language studies published between January 2011 and March 2020 in high-income, democratic countries across North America, Europe and the Asia-Pacific region. Studies were included if they focused on opinions, attitudes and acceptability of primary prevention strategies and interventions addressing the key NCD risk factors of alcohol use, unhealthy diet, overweight/obesity, tobacco use and smoking, and physical inactivity. A total of 293 studies were included. Two thirds of studies ( $n=194,66 \%)$ used quantitative methods such as cross-sectional studies involving surveys of representative $(n=129,44 \%)$ or convenience $(n=42,14 \%)$ samples. A smaller number of studies used qualitative methods ( $n=60,20 \%)$ such as focus groups $(n=21,7 \%)$ and interviews $(n=21,7 \%)$. Thirty-nine studies (13\%) used mixed methods such as content analysis of news media $(n=17,6 \%)$. Tobacco control remains the dominant topic of public opinion literature about prevention $(n=124,42 \%)$. Few studies looked solely at physical inactivity $(n=17,6 \%)$. The results of this review suggest that public opinion and acceptability of prevention in the peer-reviewed literature is investigated primarily through cross-sectional surveys. Qualitative and mixed methods may provide more nuanced insights which can be used to facilitate policy implementation of more upstream strategies and policies to prevent NCDs.
\end{abstract}

Keywords: Noncommunicable disease, Prevention, Review, Public opinion, Attitudes, Acceptability

\section{Background}

Noncommunicable diseases (NCDs) including cancers, diabetes and cardiovascular disease, are the leading causes of premature mortality and morbidity globally [1-3]. Key risk factors for NCDs include high systolic

\footnotetext{
*Correspondence: elly.howse@saxinstitute.org.au

${ }^{1}$ The Australian Prevention Partnership Centre, Sax Institute, Sydney, Australia

Full list of author information is available at the end of the article
}

blood pressure, unhealthy dietary risks, tobacco use, high fasting plasma glucose, high body mass index, high cholesterol, alcohol use and physical inactivity [4]. In 2017 these risk factors contributed to 41.1 million deaths globally (73.5\% of all deaths) [5].

Primary prevention of chronic disease focuses on addressing "upstream" environmental and social conditions that support good health across all populations and intervening before health risks and disease occur [6-8]. While some primary prevention interventions may target

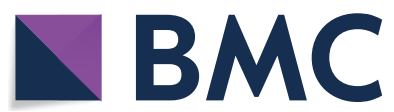

(c) The Author(s) 2022. Open Access This article is licensed under a Creative Commons Attribution 4.0 International License, which permits use, sharing, adaptation, distribution and reproduction in any medium or format, as long as you give appropriate credit to the original author(s) and the source, provide a link to the Creative Commons licence, and indicate if changes were made. The images or other third party material in this article are included in the article's Creative Commons licence, unless indicated otherwise in a credit line to the material. If material is not included in the article's Creative Commons licence and your intended use is not permitted by statutory regulation or exceeds the permitted use, you will need to obtain permission directly from the copyright holder. To view a copy of this licence, visit http://creativecommons.org/licenses/by/4.0/. The Creative Commons Public Domain Dedication waiver (http://creativeco mmons.org/publicdomain/zero/1.0/) applies to the data made available in this article, unless otherwise stated in a credit line to the data. 
individuals, such as providing information for smoking cessation, other preventive interventions involve population-level strategies that target upstream policy, systems or environment (PSE) changes.

PSE change strategies create an enabling environment or system to facilitate healthier behaviours [9-11]. Preventive interventions addressing major disease risk factors, such as overweight and obesity, physical inactivity and poor diet, ultimately require multiple changes at different levels of the system to support improvements in health [12-14]. These strategies and interventions have also been described as "low-agency" interventions, referring to the reduced reliance on conscious action of individuals to engage with healthier behaviour [15], and "optimal defaults" or healthy "choice contexts", where the healthier choice is the default option [16-19].

PSE change strategies for chronic disease prevention include measures such as mandatory nutrition labelling, sugary drinks taxes and restrictions on unhealthy food advertising [20, 21]; active transport infrastructure to promote cycling and walking [22]; minimum unit pricing of alcohol [23]; and plain packaging of tobacco products and tobacco taxes [24,25], plus "endgame" strategies that focus on a tobacco-free future [26].

Despite the evidence for effectiveness and cost-effectiveness of many of these strategies [27], chronic disease prevention remains challenging to implement. While there has been some success globally in tobacco control through regulations like the WHO Framework Convention on Tobacco Control (FCTC) [28], governments have struggled to implement interventions in other areas [29]. This is particularly the case for interventions that involve the regulation of other harmful products and industries [30]. Previous research suggests there is less support for more population-wide, environmental and regulatory measures even though they are more effective in preventing NCDs [31-33].

One barrier to implementing and sustaining any intervention in public health is the acceptability of that intervention to the target population-a key process measure within public health evaluation models [34]. Measuring the acceptability of a proposed strategy or intervention can help to identify and understand the barriers and enablers for change while helping to mobilize support for greater preventive action [35]. Decision-makers and political representatives may also be more strongly influenced by the public's opinion than by public health evidence [36, 37].

Previous reviews regarding opinion and attitudes about policies and interventions to prevent chronic disease have focused on populations and outcomes. A wide-ranging review by Diepeveen et al. [32] suggested some differences between population groups and attitudes regarding preventive interventions, including that women tend to be more supportive than men, while there was a mixed effect for age. This review also found that there is large body of research on attitudes towards tobacco control, with much of this work coming from the United States.

Other reviews of public opinion about prevention of NCDs are concentrated in tobacco control [38-40], alcohol policy $[31,41,42]$ and obesity prevention $[21,43,44]$. Reviews have also been published that examine attitudes regarding health taxes [25], sugar-sweetened beverage (SSB) taxes [45], acceptability regarding financial incentives for health-related behaviour change, [46-48], opinions on sporting food environments [49], views of the Australian population on nutrition interventions [33] and the role of the media in framing public policies to prevent chronic disease [50,51]. No reviews have been identified regarding attitudes towards physical activity interventions.

While these reviews indicate there is a substantial body of published evidence about acceptability of prevention, few, if any, reviews reflect on the methods and study designs used to collect and analyse public opinion and attitude data. Study design, question and hypothesis framing, methods (including sampling methods), response rates and types of analyses can affect perceived differences in views within and across populations, settings and countries. Furthermore, quantitative and qualitative methods are both used to understand public opinion about prevention, but the use of these methods has different purposes; these methods therefore demonstrate different types of evidence that can be used to inform policy-making and implementation of preventive interventions and policies.

\section{Review aims}

This review aims to:

1. identify, summarize and synthesize the research methods and study designs used to measure public opinion, community attitudes and acceptability of PSE change strategies and policies to prevent NCDs; and

2. consider the implications of different methods, including new and emerging methods, and discuss the challenges, gaps and opportunities of using specific methods.

\section{Methods \\ Review type}

We considered that an integrative review using systematic search methods and narrative synthesis was appropriate given the heterogeneity of the phenomena under 
investigation, the broad range of PSE change strategies and risk factors included, and the inclusion of both quantitative and qualitative methodologies with diverse study designs [52]. Our approach could also be characterized as a critical review using a comprehensive and systematic search process that produces a synthesis of evidence on a topic [53]. PRISMA [Preferred Reporting Items for Systematic Reviews and Meta-Analyses] guidelines were followed and reported on to ensure that a systematic research process was used (see Additional file 1 for the reporting checklist).

\section{Search terms}

Search terms were developed, tested and finalized by the first author in consultation with the other coauthors and an expert public health librarian. Full search terms and history can be found in Additional file 2.

\section{Database search}

Four scientific databases were searched between October 2019 and March 2020: CINAHL, Embase, Ovid (MEDLINE) and Scopus. Search results can be found in Additional file 2.

\section{Inclusion and exclusion criteria}

Table 1 summarizes the inclusion and exclusion criteria for the review.

Publications were included if they focused on the opinions, attitudes or acceptability of the public, community or population, as well as population subgroups such as policy actors. Only high-income, democratic members of the Organisation for Economic Co-Operation and Development (OECD) across Europe, North America and the Asia-Pacific Region were included to facilitate synthesis and comparisons between studies. Given the influence of democratic freedoms on the expression of public opinion [54], nondemocratic countries were excluded from the review. This approach also updates and builds on the previous review of public opinion about prevention by Diepeveen et al. [32] published in 2013. Included studies were limited from January 2011 to March 2020 to ensure manageability of the scope of the review and avoid duplication of studies included in the previous review.

As the aim of this review was to explore the methods used in peer-reviewed research about public opinion towards primary prevention of NCDs, several types of studies were excluded. Grey literature and unpublished studies were excluded. Risk factors and topics not directly relevant to the major NCD risk factors of interest were excluded: this included injury prevention, mental health and suicide, illicit drugs and breastfeeding. Also excluded from this review were views and attitudes about actual health behaviours, disease or conditions, such as views or attitudes about obesity, unless the major focus of the study was views and attitudes about the policies, strategies or interventions to prevent obesity, for example. A study on the acceptability of an intervention or policy was not included if it was not the major focus of the article, such as a minor part of a broader process evaluation for a programme. We also excluded studies which examined the acceptability of financial-based interventions such as payments for weight loss, as the focus of the review was not on individual-based interventions. The views and opinions of healthcare professionals, clinicians and patients were excluded given the focus of this study was the attitudes of the broader "public" and not only those with a professional or expert interest in health and healthcare.

Some study designs were also excluded, such as formative and experimental studies (those that test the effects or preferences of different messages or frames by different groups and their resulting opinions or attitudes), as this review aimed to analyse descriptive studies of public opinion. We also excluded reviews (including systematic reviews) and meta-analyses to avoid a double-count of original studies.

\section{Screening process}

The first author (A1) completed all database searches, extracted the results and removed duplicates. A1 completed an initial screen of titles and abstracts, removing those outside of the years, countries and risk factors identified. A1 and A2 then screened titles and abstracts using Covidence [55], double-screening 20\% to achieve concordance. A1 and A2 completed the full-text screening and agreed on final inclusion of articles in the review.

\section{Data extraction and analysis}

A1 and A2 developed and tested the data extraction tool in Covidence. Included studies were then extracted by A1 from Covidence. The following data were extracted:

- Title of study

- Country or countries of study

- Research type

- Study design

- Chronic disease risk factor or topic group

- Population group

- Setting

- Total number of participants

- Summary of main findings

- Other notes, including details about recruitment, further information about study type and response rate for surveys. 
Table 1 Inclusion and exclusion criteria

\begin{tabular}{|c|c|c|}
\hline & Inclusion & Exclusion \\
\hline Publication date range & Published between January 2011 and March 2020 & Published prior to 2011 or after March 2020 \\
\hline Language & English & Non-English language \\
\hline Countries & $\begin{array}{l}\text { High-income, democratic countries in the Asia-Pacific, } \\
\text { Europe (including Scandinavia) and the European } \\
\text { Union, North America, Great Britain and/or OECD } \\
\text { Cross-country studies such as the ITC Study (including } \\
\text { the above countries or pan-Europe) }\end{array}$ & $\begin{array}{l}\text { Nondemocratic countries } \\
\text { Low- or middle-income countries } \\
\text { Countries outside the regions specified }\end{array}$ \\
\hline Type of publication & $\begin{array}{l}\text { Original studies or empirical research published in } \\
\text { peer-reviewed journals }\end{array}$ & $\begin{array}{l}\text { Letters } \\
\text { Editorials } \\
\text { Commentary } \\
\text { Opinion pieces } \\
\text { Essays } \\
\text { Reviews } \\
\text { Protocols } \\
\text { Grey literature } \\
\text { Unpublished research }\end{array}$ \\
\hline Type of research & $\begin{array}{l}\text { Quantitative } \\
\text { Qualitative } \\
\text { Mixed methods }\end{array}$ & \\
\hline Study design & $\begin{array}{l}\text { Representative cross-sectional survey } \\
\text { Nonrepresentative (convenience) cross-sectional survey } \\
\text { Longitudinal or serial study } \\
\text { Focus group } \\
\text { Interviews } \\
\text { Media analysis } \\
\text { Deliberative study (e.g. citizen jury) } \\
\text { Consultations / Delphi processes } \\
\text { Other }\end{array}$ & $\begin{array}{l}\text { Experimental studies (e.g., framing effects) } \\
\text { Systematic or other type of review } \\
\text { Meta-analyses }\end{array}$ \\
\hline Population & $\begin{array}{l}\text { General population ("public"/citizens) } \\
\text { Children or adolescents } \\
\text { Adults } \\
\text { Staff/employees } \\
\text { Students } \\
\text { Academics } \\
\text { Policy-makers and practitioners } \\
\text { Politicians/representatives }\end{array}$ & $\begin{array}{l}\text { Patients } \\
\text { Healthcare professionals and clinicians e.g., doctors, } \\
\text { pharmacists }\end{array}$ \\
\hline Risk factors & $\begin{array}{l}\text { Improve diet, food or nutrition, including sugar-sweet- } \\
\text { ened beverages } \\
\text { Physical inactivity } \\
\text { Alcohol use } \\
\text { Overweight and obesity } \\
\text { Tobacco use or smoking }\end{array}$ & $\begin{array}{l}\text { Mental health and suicide } \\
\text { Illicit drugs } \\
\text { Injury prevention not linked to the included risk factors } \\
\text { Other public health topics (e.g. abortion, vaccination, } \\
\text { sexual health/HIV) } \\
\text { Breastfeeding } \\
\text { E-cigarettes and tobacco cessation practices }\end{array}$ \\
\hline Main outcomes measured by study & $\begin{array}{l}\text { Opinion, view, attitude, belief or support regarding } \\
\text { primary prevention of lifestyle-related chronic disease, } \\
\text { such as laws, regulation, policies, taxation, labelling, } \\
\text { restrictions, bans, government intervention, or any } \\
\text { other PSE change strategy }\end{array}$ & $\begin{array}{l}\text { Attitudes or beliefs about health, risk factors, diseases, } \\
\text { conditions or treatment } \\
\text { Opinions or attitudes about secondary or tertiary } \\
\text { prevention of chronic disease (such as views on weight } \\
\text { loss interventions, smoking cessation/e-cigarettes, and } \\
\text { pharmaceutical interventions) } \\
\text { Attitudes or beliefs relating to a process evaluation } \\
\text { (implementation) of a programme or intervention } \\
\text { Health promotion or health education practices and } \\
\text { programmes }\end{array}$ \\
\hline
\end{tabular}

ITC International Tobacco Control Study, OECD Organisation for Economic Co-operation and Development, PSE policy, system or environment

Data about country, study design or method and population were grouped into larger categories agreed upon by authors A1, A2, A5 and A6 for descriptive analysis. Quantitative methods included cross-sectional study designs and cohort studies. Qualitative methods included focus groups, interviews, deliberative processes and some types of media analyses. Mixed methods included those that involve both quantitative and qualitative methods, such as content analysis of news media. 
A quality assessment was not conducted given the broad range of methods and study designs included. However, data such as recruitment, sample size/number of participants and survey response rates were collected during the data extraction stage.

\section{Results}

A total of 11,084 titles were identified through database search $(n=10,791)$ and manual search of reference lists of relevant reviews and literature $(n=293)$. Duplicates $(n=2044)$ were removed, leaving 9040 titles which were further screened for relevance, with a further 8241 titles then excluded. A total of 799 abstracts and titles were screened. The full texts of 460 articles were then screened, and of these, 293 articles were included for analysis (Fig. 1 PRISMA diagram).

The full list of included studies with summary of key data extracted can be found in Additional file 3.

\section{Summary of included studies}

Two thirds of the included studies used quantitative methods ( $n=194,66 \%)$, with a smaller number using qualitative methods $(n=60,20 \%)$ or mixed methods (both qualitative and quantitative methods) $(n=39,13 \%)$ (Table 2, Methodology and design of included studies).

Quantitative methods included cross-sectional studies of a sample or population, such as surveys of representative $(n=129,44 \%)$ or convenience/purposive $(n=42$, $14 \%)$ samples and longitudinal cohort studies $(n=23$, $8 \%)$. Qualitative data collection methods included focus groups $(n=21,7 \%)$, interviews $(n=21,7 \%)$, qualitative media analysis $(n=8,3 \%)$ and deliberative methods $(n=5,2 \%)$. Mixed methods included media analysis studies with qualitative and quantitative methods, for example, content analysis $(n=17,6 \%)$. Other studies in this category included 12 studies (4\%) with multiple study designs incorporating both qualitative and quantitative methods, for example, using focus groups and a survey.

Most studies were conducted at the national level $(n=124,42 \%)$, followed by local level $(n=85,29 \%)$, state or regional level $(n=59,20 \%)$, and international $(n=25$, $9 \%)$. The largest number of studies were conducted in North America (United States or Canada, $n=126,43 \%$ of total). Studies from Australia and New Zealand formed a quarter of the studies $(n=76,26 \%)$, while studies in other countries were less frequent (United Kingdom and Ireland, $n=32,11 \%$; Europe, $n=30,10 \%)$. Nine percent of studies $(n=25)$ were conducted across multiple countries and were deemed "international" studies.

Over half of the studies focused on the general public $(n=163,56 \%)$. Fewer studies focused on specific populations, such as policy actors $(n=27,9 \%)$, which included government policy-makers, politicians, advocates, lobbyists, academics, retailers and/or industry $(n=27$, $9 \%)$. Other population groups included children, adolescents or young adults $(n=19,6 \%)$, smokers or former smokers $(n=15,5 \%)$ and university/college students or staff $(n=14,5 \%)$. A small number of studies looked at multiple populations and groups $(n=15,5 \%)$. Other community groups $(n=7,2 \%)$ included public housing residents, Indigenous or culturally and linguistically diverse people and migrant groups.

Over two fifths of studies $(n=124,42 \%)$ were focused on opinions and attitudes regarding prevention of tobacco use and smoking (Fig. 2, Number of studies by risk factor or topic).

Other risk factors or topics included alcohol use $(n=41,14 \%)$, improving diet $(n=38,13 \%)$ and overweight and obesity $(n=37,13 \%)$. A smaller number of studies addressed SSBs $(n=22,8 \%)$. Only 17 studies $(6 \%)$ looked at attitudes about preventive interventions regarding physical inactivity. Thirteen studies (4\%) focused on interventions targeting multiple risk factors or the topic of prevention more generally.

\section{Quantitative methods}

\section{Cross-sectional study-representative samples}

Over half of these studies ( $n=77,26 \%)$ used a single survey design, that is, conducted once. A smaller number of studies analysed repeat or serial surveys using the results of a single survey wave $(n=27,9 \%)$ or by comparing the results of multiple survey waves $(n=25,9 \%)$.

Single surveys These studies tended to be of the general public, mostly sampled at a national (country) level $(n=42,14 \%)$. Single surveys with regional samples $(n=20$, $7 \%$ ) were most often found in larger countries with state jurisdictions, such as the United States or Canada. Examples of these studies included public support for an SSB tax in Kansas, United States [56] and interventions targeting SSBs in Quebec, Canada [57]. Single, local-level representative surveys $(n=10,3 \%)$ also tended to be from the United States, such as support for nutrition PSE change strategies in Los Angeles [10].

Tobacco use was a commonly addressed risk factor in cross-sectional studies using a single survey design $(n=30,10 \%)$. Half of these $(n=15)$ were conducted in the United States. Surveys were also conducted about increased regulation of tobacco in Australian states [58, 59], New Zealand [60-62] and Scandinavian countries [63]. A small number of single surveys were conducted across multiple countries to compare community attitudes regarding tobacco control in different sociopolitical contexts $[64,65]$.

Less common risk factors covered by single surveys included improving diet $(n=10)$, alcohol use $(n=9)$, 
Records identified through database searching ( $n=10,791)$
Additional records identified through other sources

$(n=293)$
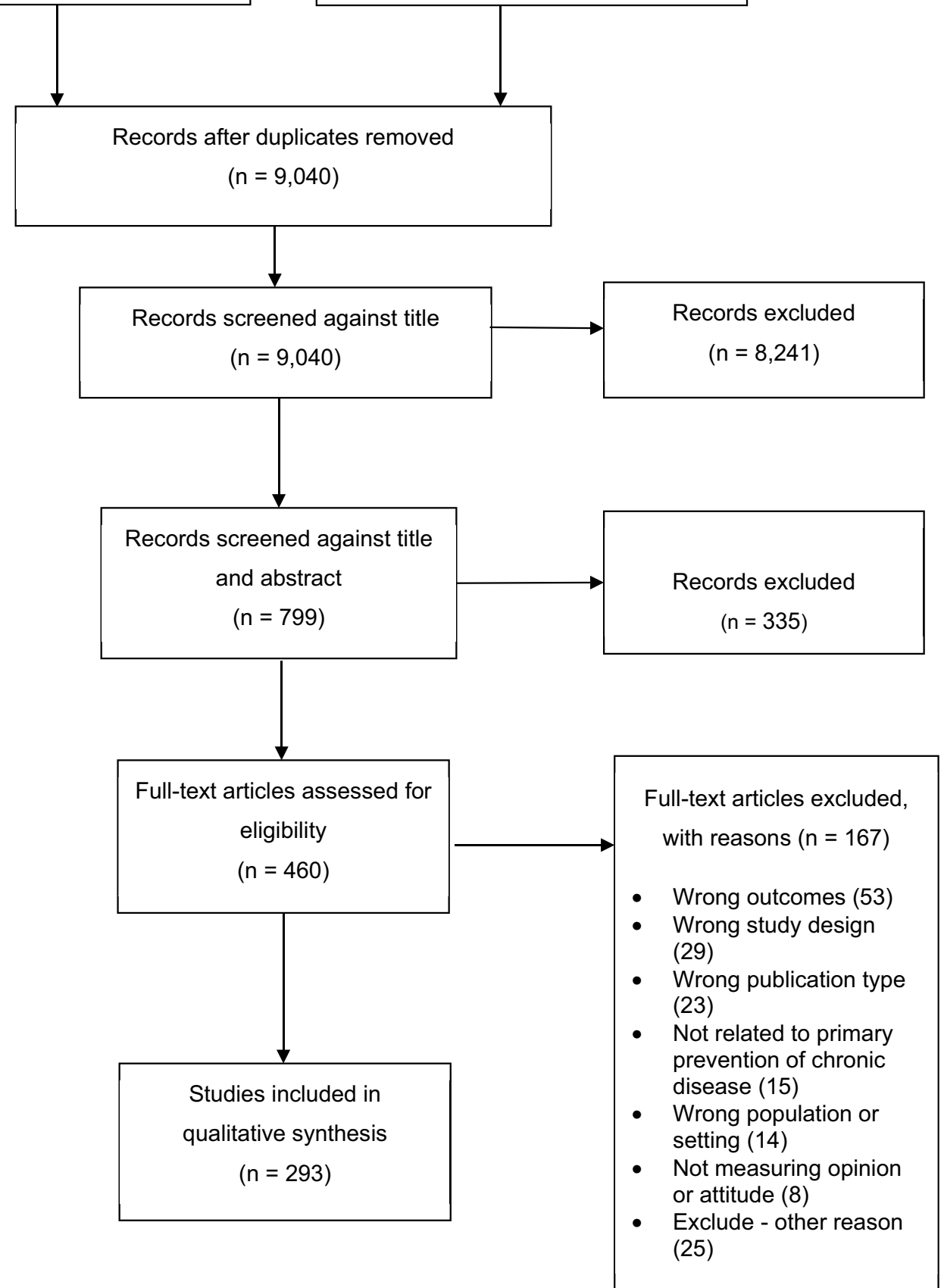

Fig. 1 PRISMA diagram

obesity $(n=8)$ and SSBs $(n=8)$. Only seven studies asked about physical inactivity interventions; six of these studies were in North American populations, and were focused on views about active transport measures in the United States [66, 67].

A further seven studies considered views about a broad range of interventions to address chronic disease, 
Table 2 Methodology and design of included studies

\begin{tabular}{lll}
\hline & Included studies & $\begin{array}{c}\text { Proportion } \\
\text { of total } \\
\text { studies }\end{array}$ \\
\hline Quantitative & & $66 \%$ \\
Cross-sectional study_representative sample & 194 & $44 \%$ \\
Cross-sectional study_convenience or purposive sample & 129 & $14 \%$ \\
Cohort study & 42 & $8 \%$ \\
Qualitative & 23 & $20 \%$ \\
Interviews & 60 & $7 \%$ \\
Focus groups & 21 & $7 \%$ \\
Media analysis & 21 & $3 \%$ \\
Deliberative (e.g. citizen's jury) & 8 & $2 \%$ \\
Document or submission analysis & 5 & $<1 \%$ \\
Multiple qualitative methods & 3 & $<1 \%$ \\
Mixed methods & 2 & $13 \%$ \\
Media analysis & 39 & $6 \%$ \\
Multiple quantitative and qualitative methods & 17 & $4 \%$ \\
Cross-sectional survey_convenience sample & 12 & $2 \%$ \\
Document or submission analysis & 7 & $<1 \%$ \\
Community-based participatory & 1 & $100 \%$ \\
Total & 1 & 293 \\
\hline
\end{tabular}

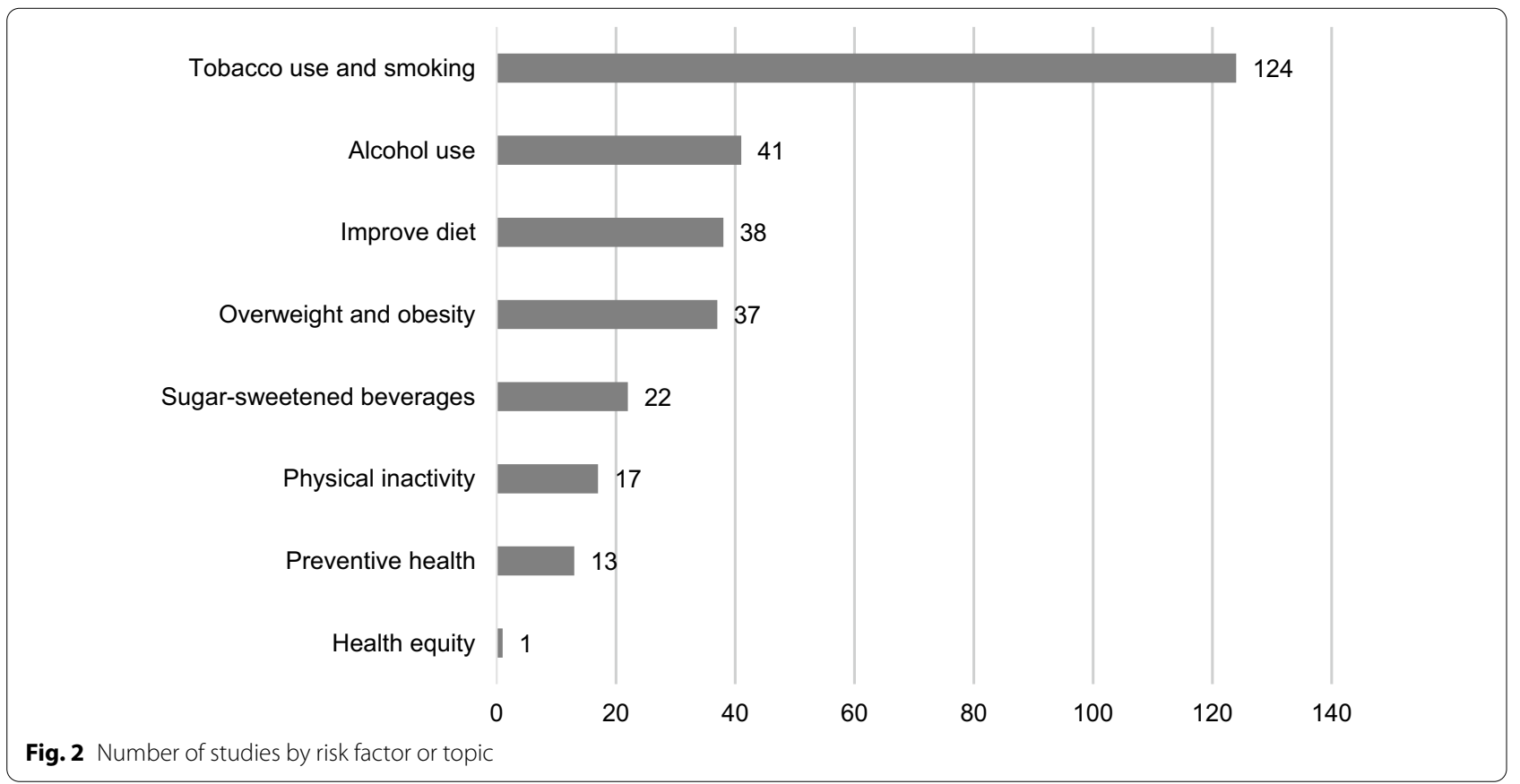

including a survey of Canadians about health equity interventions [68] and six surveys asking about preventive health interventions addressing multiple risk factors [69-72].
Repeat or serial surveys Some cross-sectional studies used repeat or serial surveys, with data collected in different "waves" over time. These studies generally used the same survey questions but with different samples each 
time. In this section we have included studies that analysed both one wave and multiple waves.

Six studies analysed results from SummerStyles (formerly HealthStyles), a market research survey of United States adults run several times a year that collects healthrelated opinions and attitudes. These studies mainly analysed data from views regarding tobacco control [73-76], though one study was about attitudes regarding urban design to promote physical activity [77] and another about improving fruit and vegetable access [78].

Other examples of major cross-sectional serial surveys include the Eurobarometer survey, a cross-national survey conducted by the European Commission several times per year, including both standard modules and special topic modules in various public policy areas. Each survey wave usually includes over 20,000 participants. In recent years this survey has included questions on attitudes towards tobacco control measures [79-82] and policies to address childhood overweight and obesity [83]. Other international studies had very large samples, such as tens of thousands of participants in multiple countries, in order to compare views about alcohol policies across Europe [84].

Some national-level, long-running serial surveys that tracked public opinions over time were also identified in this review, with studies analysing data from the Social Climate Survey of Tobacco Control in the United States, running since 2000 [85-87]; the National Adult Tobacco Survey, run by the Centers for Disease Control and Prevention in the United States since 2009 [88-91]; and the National Drug Strategy Household Survey in Australia, running since 1995 [92-94]. Other studies used the same survey questionnaire at several points in time to measure changes in attitude and support, for example three national surveys on alcohol control attitudes of 1000 Irish adults in 2002, 2006 and 2010 [95], and a comparison of attitudes about tobacco control across two universities in the United States [96].

Serial surveys of adolescents' views about prevention policies were also identified, such as tobacco control surveys in the United Kingdom [97], New Zealand [98] and California, United States [99]; and across multiple policy areas in Europe [100].

\section{Cross-sectional study - convenience or purposive sample}

Some studies used convenience or purposive samples for quantitative cross-sectional surveys of public opinion $(n=42,14 \%)$. These were usually to support implementation locally or regionally-most of these studies $(n=35$, $12 \%)$ were conducted in a local or state setting.

Cross-sectional studies using convenience samples were more likely to be surveys of groups or subpopulations, focused on measuring the acceptability of smoke-free settings. For example, eight studies were conducted in a university or college population, seven of which were specifically focused on tobacco control and smoke-free campuses. Other similar studies considered views of employees and managers regarding smoke-free hospitals $[101,102]$ and public housing residences [103, 104]. Numbers of participants within such settings were much smaller than for other types of cross-sectional surveys, with 1000 or fewer participants in each survey.

Other studies in this category included five studies of policy actors, influencers or stakeholders, including an intercept survey of local retailers' views about smokefree shopping streets in Wellington, New Zealand [105]. The other four studies included a survey of political representatives' support for obesity reduction policies in the United States [106]. These studies again had much smaller numbers of participants (i.e., 200-500 participants) and tended to utilize purposive sampling methods.

\section{Cohort study (including sub-studies)}

Many prospective or longitudinal cohort studies $(n=23$, $8 \%$ ), also known as panel surveys, were identified in this review. This group included both cross-sectional substudy surveys (at one point in time) within a cohort study $(n=15)$ and ongoing tracking of the cohort over time $(n=8)$. Most cohort studies were in tobacco control $(n=19)$. For example, the Indiana University Smoking Survey $[107,108]$ is a longitudinal cohort study tracking adolescents' attitudes about tobacco control over time.

One key type of cohort study identified in this review is the International Tobacco Control (ITC) Policy Evaluation Project [109], a major collaborative effort across 29 countries to measure and track the impact of nationallevel WHO FCTC policies including advertising bans, labelling, smoke-free legislation and taxation of tobacco products. The ITC study surveys the general public as well as former and current smokers. Twelve studies included in this review came from the ITC study, both across multiple countries as well as country-level specific studies, including the general public in Canada [110], France [111] and New Zealand [112]. Seven of these studies were cross-sectional sub-study surveys drawn from the ITC cohort, including comparative surveys across multiple countries $[113,114]$.

Of the other 15 cross-sectional sub-study surveys identified, two were drawn from existing prospective cohort studies in Australia. One sample among parents participating in a birth cohort study surveyed them about policy preferences for preventing childhood obesity [115]. Another survey looked at support for active transport policies amongst a cohort of cyclists [116]. The other sub-studies were drawn from the NutriNet-Santé cohort study in France [117] and the International Food Policy 
study looking at support for healthy food policies and diets across five countries [118].

\section{Qualitative methods Focus groups}

The focus group studies $(n=21,7 \%)$ were mostly recruited from and conducted within local settings, exploring a range of prevention strategies targeting alcohol use $(n=6)$, tobacco use $(n=5)$ and improving diet $(n=4)$. Several studies were identified that explored specific interventions with a higher level of public contestability, such as alcohol taxation and pricing [119-122] and public attitudes towards preventive pricing policies [123].

While recruiting from the general public was a common source for focus groups $(n=12)$, focus groups studies were also used with specific groups such as adolescents $(n=5)$-for example, understanding how adolescents in the United Kingdom felt about healthier food in school canteens [124] and adolescent views regarding SSB taxes in the United States [125]. This was also the case for those studies that explored more marginalized socioeconomic groups, such as those regarding obesity prevention [126] and promoting fruit and vegetable access [127].

Focus groups were used in specific settings such as workplaces to understand employees' perceptions of workplace-based interventions to promote physical activity [128] and university students' attitudes regarding campus alcohol policies [129, 130].

The total number of participants varied across the included studies, from 24 participants in one group to 218 across 28 focus groups.

\section{Interviews}

Interviews were another qualitative design used $(n=21$, $7 \%)$. Interviews were commonly used to explore the opinions and attitudes of policy actors $(n=16)$, mainly regarding obesity prevention and tobacco control policy measures. Specific policy or research areas were explored using semi-structured and in-depth interviews, for example about alcohol regulation and taxation in Australia [131] and reducing tobacco availability in New Zealand [132]. Some studies also interviewed policy actors about food-related taxes and subsidies [133] and nutrition labelling [134] in New Zealand and childhood obesity prevention in Spain [135]. One study looked at the differences in views about obesity prevention priorities and strategies among 20 politicians in one state of the United States compared to advocates' views [136].

Four studies were identified that specifically focused on understanding the opinions and attitudes of retailers and industry. Three of these studies were about tobacco control interventions, such as smoke-free pubs and bars
[137] and tobacco "endgame" strategies in New Zealand $[138,139]$. The remaining study included interviews with recreation centre managers regarding pricing interventions to promote healthier food choices [140].

Some studies recruited from specific community groups, such as interviews with more marginalized or less studied communities-for example, interviewing children about restricting junk food marketing in New Zealand [141] or interviewing adolescents about nutrition interventions in disadvantaged communities in Australia [142], and interviewing disadvantaged and lowincome smokers about increased tobacco control regulation $[143,144]$.

\section{Media analysis-qualitative}

Qualitative media analysis studies $(n=8,3 \%)$ involved news media analysis $(n=3)$, analysis of reader comments on news stories $(n=3)$ and social media analysis $(n=2)$. These studies were from the United States $(n=3)$, United Kingdom $(n=3)$, Australia $(n=1)$ or multiple countries $(n=1)$.

Three studies analysed English-language print and/ or online news media reporting on obesity and tobacco control. One study used framing analysis to look at how newspapers over a 10-year period reported on childhood obesity in the United States [145]. Another study reviewed news media articles on solutions to address childhood obesity over a 20-year period, comparing and contrasting reporting across three countries, the United States, Canada and the United Kingdom [146]. At a state level in the United States, Kuiper et al. [147] analysed news coverage of smoke-free laws in Michigan.

Two studies used social media analysis to measure and understand public opinion about a specific preventive topic. Astill Wright et al. [148] analysed tweets about minimum unit pricing of alcohol in Scotland. Feng et al. [149] also analysed Twitter regarding proposed new tobacco taxation levels in California.

Three of the media analysis studies examined reader commentary on news media articles. One study analysed over 3600 comments on 83 news media stories in Australia focused on obesity [150]. Another study analysed 1645 reader comments on articles about SSB taxation in the United Kingdom [151].

\section{Deliberative processes and citizens' juries}

A small number of qualitative studies $(n=5,2 \%)$ used a deliberative process, such as a citizens' jury, to study public opinion and attitudes. All studies were conducted in Australia at a local or state level using a range of recruitment methods, such as purposive sampling, market research recruitment or recruitment from an existing survey population. 
Four of these studies recruited participants from the general population, using 13-20 participants per study. Two were focused on improving diet, such as exploring and understanding attitudes about food policy [152], and the regulation of fast food through a corporate health impact assessment [153]. Another study used a citizens' jury design to understand whether the government should tax SSBs [154]. The other study looked at community attitudes regarding regulations and laws for childhood obesity prevention [155].

Only one deliberative study was conducted with a specific population. Street et al. [156] ran a community deliberative forum in an Australian town with a local Aboriginal community, exploring what preventive areas and programmes government should invest in to support Aboriginal youth well-being, exploring policy options as well as broader issues such as structural racism and socioeconomic disadvantage.

\section{Document or submission analysis}

Qualitative studies using document or submission analysis $(n=3,1 \%)$ were analyses of parliamentary proceedings and submissions made by stakeholders or members of the general public regarding interventions for alcohol use and diet.

One study analysed industry submissions to a parliamentary inquiry on alcohol, focusing on identifying the tactics used by the alcohol industry to create barriers to preventive alcohol policy in Australia [157]. A similar study was conducted in New Zealand, comparing submissions from the general public, advocacy groups and alcohol industry to explore how different groups responded to a proposal to increase the alcohol purchasing age [158]. Another study looked at Australian politicians' presentation of public health nutrition issues, using framing analysis of parliamentary transcripts to understand their views on the causes of and solutions to childhood obesity and junk food marketing to children [159].

\section{Multiple qualitative methods}

Two studies used a combination of study designs with qualitative methods. Katikireddi and Hilton [160] analysed news media, policy submissions and in-depth interviews to compare the ways in which different policy actors influenced public opinion on the topic of alcohol minimum unit pricing in Scotland. The other study in this category included interviews with policy actors and stakeholders in New Zealand (including the tobacco industry) alongside focus groups with smokers, looking at support for low-nicotine-content cigarettes [161].

\section{Mixed methods \\ Media analysis}

Some media analysis studies involved both quantitative and qualitative methods $(n=17,6 \%)$ such as content analysis of English-language news media articles $(n=15)$, social media $(n=1)$ and reader commentary on news media $(n=1)$.

Six studies analysed news media coverage of tobacco control measures, such as smoke-free laws in Canada or the United States $[162,163]$ and bans in the United Kingdom on smoking in cars carrying children [164, 165]. SSB taxation was another popular topic for mixed-method media content analysis during this period, with four studies covering this issue by analysing stakeholders' views in news media in the United Kingdom [166-168] and in the United States [169]. In terms of alcohol use, two studies conducted content analysis of United Kingdom newspapers to explore how alcohol minimum unit pricing was represented in the media by different groups [170, 171]; a similar study from Australia examined news media coverage of alcohol advertising restrictions [172]. Only one study was identified that used both quantitative and qualitative media analysis to look at news reporting of views about solutions to childhood obesity [173].

Two studies included in this category conducted content analysis of different media platforms. One study looked at tweets on a United States school meals policy, using opinion-mining techniques and content analysis [174]. Freeman [175] analysed 117 online news items (including opinion polls) and reader comments on Australian news media platforms to understand support and opposition to tobacco plain packaging prior to implementation.

\section{Multiple quantitative and qualitative methods}

Multiple designs or methods $(n=12,4 \%)$ encompassed the use of quantitative and qualitative methods, for example conducting a quantitative cross-sectional study as well as using qualitative methods such as focus groups and/or interviews $(n=10)$.

Some studies used qualitative methods as formative research to inform subsequent cross-sectional survey design. Grunseit et al. [176] conducted focus groups with members of the general public regarding views and attitudes about preventive health in Australia, which then informed the development of a national cross-sectional survey about prevention. Booth et al. [177] also used this approach with a purposive (rather than representative) sample; they interviewed school policy actors in the United Kingdom about childhood obesity prevention, with the results informing a cross-sectional survey for a wider group of stakeholders. 
Other studies conducted the quantitative and qualitative elements alongside one another. One study from Australia conducted an online survey about strategies to promote public transport use, with "nested" focus groups and interviews [178]. A similar study in the United Kingdom conducted a representative survey of adults regarding views on preventive alcohol policies, from which focus group participants were recruited to explore the topic in greater depth [179]. Other mixed-methods studies conducted in specific settings (e.g., schools or universities) used a similar methodological design (survey plus focus group and/or interviews) to look at acceptability of alcohol measures in Spain [180] or tobacco control in the Netherlands [181].

A small number of studies used other mixed methods, for example conducting document analysis of legislative bills about calorie menu labelling in California in conjunction with news media content analysis to understand how different policy actors shaped the public debate over time [182]. Mah et al. [183] also looked at calorie menu labelling in Canada, using results from a public survey and comparing these with the findings from a survey and policy consultation with hospitality industry stakeholders. Another study recruited 95 members of the general public in New York, United States, to explore views about what communities could do to prevent childhood obesity; the authors first conducted a survey, used Q methodology (to sort statements of participants based on their agreement, views and feelings), followed by structured interviews [184].

\section{Cross-sectional survey}

A small number of studies $(n=7,2 \%)$ utilized crosssectional surveys that had both closed- and open-ended responses, with thematic or content analysis often used to analyse the open-ended responses; as such, these have been included as "mixed methods". Over half of these studies were with multiple groups or a specific population at the local level, such as exploring views and attitudes about a health-promoting setting-for example, surveys with university students and staff regarding SSB regulation on campus [185], employee attitudes about a smoke-free hospital campus [186] and views about bikesharing infrastructure in a Swedish city [187].

\section{Other study designs}

Other mixed methods were used in a small number of studies $(n=3,1 \%)$. These included a Delphi study of policy actors and stakeholders regarding views on physical activity policy measures in the Netherlands [188], a community-based participatory study with policy actors involving concept mapping to promote physical activity in local communities across the United States [189] and a content analysis of public comments in the United States regarding changes to public health nutrition standards [190].

\section{Discussion}

This review is the first to identify and synthesize the methods and study designs used to describe the acceptability of preventive measures and policies to address lifestyle-related chronic disease in high-income, democratic countries across Europe, North America and the AsiaPacific region.

We identified four major outcomes from this review that have implications for future research directions. First, quantitative cross-sectional study designs are the predominant way in which public opinion about NCD prevention is measured and understood. Second, while qualitative and mixed methods are used less frequently, they may provide an important value add for understanding public opinion which could assist implementation of preventive policies. Third, tobacco control forms a significant portion of the literature, which may have facilitated or contributed to improved policy implementation, with flow-on effects for improving health outcomes. Finally, only a small number of studies considered public opinion about topics such as physical inactivity, indicating a data gap for this area of prevention. Below we take each of these findings and explore their implications for future research.

\section{Cross-sectional studies are the predominant method for public opinion data}

We found that the literature published during the time frame of inclusion relies heavily on quantitative methods, particularly cross-sectional study designs. The reliance on such study designs has implications for the way in which researchers and policy-makers conceptualize and collect data on public opinion, which then affects how we understand this phenomenon. While we did not conduct a quality assessment of all the studies, we make some general comments about the possible challenges in using such methods and study designs.

In public opinion research, cross-sectional studies are the most commonly used method, aiming to provide a "snapshot" of the public's attitudes at a specific point in time [191]. Most public opinion surveys about prevention identified in this review used representative, probability or random sampling techniques, including recruiting from market research groups and weighting results based on the demographic distribution of the studied population, usually at a national (country) level. Nonresponse bias can arise in terms of study selection, particularly from telephone-based surveys, which can influence the reliability and accuracy of the results [192]. Generally, the 
lower the response rate the more doubt there could be about the representativeness of the population and their responses [193]. As such, the reported opinions of many of these studies may not be truly representative of the population, though we note that surveys in this review did use larger sample sizes to account for uncertainty, and generally recorded response rates as part of their methods and/or limitations. However, these surveys may still reflect a selective view of what the "majority" thinks, with criticism that survey research relies on capturing a "narrow dimension of public attitudes" [194].

There is also the possible issue of social desirability bias, where survey participants respond based on perceptions about the desirability of certain behaviours over others [195]. This could apply to preventive interventions about behaviours or conditions that are stigmatized, such as smoking or obesity. For example, Knox et al. [196] found some evidence of social desirability bias in a study of United States adults regarding SSB consumption and perceptions about the health and economic benefits of SSB taxation. It is possible that the surveys included in this review experienced some social desirability bias, though equally that could apply to qualitative and other methods that involve discussing topics in front of others (such as focus groups).

Other challenges with relying on cross-sectional survey data for public opinion about prevention include measurement comparability. There is no one standardized approach to measuring people's opinions either individually or collectively [191], though some studies such as serial or repeated surveys use the same questions over time, and market research companies may conduct pretesting strategies to validate the survey instrument. Regardless, there are still issues in terms of reliability and comparability if different surveys are using different instruments. These issues can also apply between different survey modalities, such as telephone-based surveys versus internet surveys [197].

While well-run cross-sectional surveys are useful, the results from these studies represent one type of evidence or representation of public opinion and acceptability, rather than the only type. This point has been noted in other studies that incorporate diverse forms of quantitative and qualitative evidence in defining the "acceptability" of interventions [198].

\section{Qualitative and mixed methods have a value add for this area of research}

Our findings suggest that while qualitative and mixedmethods research on opinions and attitudes were much less commonly used than quantitative methods, they may play an important and complementary role. Although quantitative methods may help to explain the "what" people think about a certain question, they can't tell "why" people may hold those views-the beliefs, values, ideologies and ethical positions of participants. Qualitative and mixed methods can help build a richer picture of public opinion, explore why people hold opinions and attitudes, and look at broader assumptions, values, and beliefs about health, government and responsibility [176].

We found examples of studies that used different methodological approaches in a complementary way. Li et al. [179] used mixed methods (cross-sectional survey and focus groups) to explore attitudes about alcohol control policies in the United Kingdom. Somerville et al. [123] noted the importance of using qualitative methodology, such as focus groups, to complement quantitative methods in acceptability studies in public health. These methods can help to illustrate that people's views on policies develop through interactions with others. In other words, expression of support (or disagreement) with a policy or intervention is not static but part of a dynamic process of opinion formation [194].

We also identified some novel and innovative methodological approaches in the qualitative literature. Social media analysis of Twitter users provided insight into the salience of a specific and contested preventive policy, such as minimum unit pricing of alcohol in the United Kingdom [148]. Social media provides one avenue for the public to comment on public health interventions outside of traditional polling methods, and could be particularly useful when studying examples of policy implementation failure, such as in the case of California's attempt to increase tobacco taxation [149]. However, there is caution about how much these platforms are representative of the "public" or community at large. This is particularly important given that unhealthy industry groups may use social media platforms such as Twitter as part of their lobbying strategy to influence public and political opinion [199].

Other innovative methods we identified that provide a rich body of evidence included deliberative methods, which can generate ideas on policy solutions from participants as well as observing and understanding the process of change in opinions and attitudes [153], and " $Q$ methodology", which was used to find common ground across the general public for childhood obesity prevention and to identify the least contested strategies which could be acceptable [184].

There is moreover a vital role for qualitative methods in terms of giving "voice" to underserved, vulnerable or marginalized groups that may be left out of larger national quantitative surveys. Examples include focus groups with children and adolescents, particularly in disadvantaged areas [142], in-depth interviews of lowincome smokers [143] and a deliberative dialogue with 
an Aboriginal community regarding youth well-being [156]. Qualitative research has a powerful part to play in addressing inequities in research, particularly in public opinion research which has tended to empirically focus on what the "majority" think through public polls and surveys. However, we do note the limitations of study designs like focus groups, which can have a different kind of "majority opinion" effect on participation; this has been identified in other reviews of the literature [33].

\section{Learning from tobacco control about public opinion and acceptability}

This review identified that tobacco control has a much larger published evidence base about attitudes and opinions compared to the other risk factors included in this study. It is possible such an extensive evidence base has likely facilitated or contributed to policy implementation of tobacco control strategies in the countries included in this review.

Most tobacco control studies were predominantly annual cross-sectional surveys with large samples across multiple countries. Multi-country surveys are useful for being able to place public opinion about prevention within a specific sociopolitical and policy context-for example, demonstrating that increased tobacco control implementation at a country level is positively related to the social denormalization of tobacco and linked with increased support for existing or proposed tobacco control measures [81]. A similar relationship exists in terms of support for tobacco "endgame" strategies and the advanced implementation of country-level tobacco control policies [64]. Some of these surveys were also conducted in multiple "waves" which could detect temporal changes. This type of evidence could be persuasive for political leaders and policy-makers who are unsure about implementing new preventive interventions and policies, but we note that such long-running international surveys are both expensive and time-consuming.

In tobacco control, we also found cohort studies for tracking public opinion and attitudes. The benefit of these studies is that they can detect associations between exposure-for example, adolescents' exposure to increasing implementation of tobacco control measures-and changes in views and attitudes [107, 108, 200]. Studies like the ITC Study have contributed enormously to knowledge and evidence about the acceptability of tobacco control to inform policy implementation. It is therefore promising to see similar studies developed in other areas of prevention, such as the International Food Policy Study [118]. Such studies are costly but valuable sources of evidence, as public opinion data from these kinds of study designs may help to distinguish between age, period or cohort effects [201, 202].
This is an important methodological question for public opinion research, given the challenges of measurement error and bias and the reflection of past views in crosssectional surveys [203]. Given the large numbers of existing longitudinal cohort studies tracking preventive health behaviours, researchers may wish to consider attitudinal questions and measures as part of data collection, especially those in other areas of prevention outside of tobacco control.

In addition, there were many local-level convenience or purposive surveys and setting-specific surveys about tobacco control. While these may be a less rigorous form of evidence compared to large nationally representative surveys, they are still useful (and cheaper) at providing a snapshot of community views, which may facilitate locallevel policy implementation, such as prior to introducing policies or guidelines, or "temperature-testing" of new interventions. This could explain why many of the included studies using this type of method were focused on smoke-free regulations in specific settings like universities, public places or hospitals, with findings that could be useful for improved health policy implementation.

\section{Public opinion about physical inactivity—an evidence gap?}

Our review demonstrates that physical inactivity was rarely the focus of studies looking at opinions and attitudes. This finding echoes that of the review by Diepeveen et al. [32], which identified a small number of studies looking at people's views and attitudes about prevention policies and interventions relating to physical inactivity. This gap could be for several reasons.

While there has been increased focus on physical inactivity as a major risk factor for chronic disease, particularly with the development of international strategic frameworks such as the global action plan on physical activity [204], the findings from our review suggest a major evidence gap in terms of understanding people's acceptability and opinions about interventions. Generating such evidence could assist governments in implementing such frameworks and recommended policies. Monitoring policy support is one type of "macro-level determinant" for physical activity that needs to be included as part of population surveillance [205].

Some have commented that physical inactivity is the so-called Cinderella risk factor in chronic disease prevention, receiving little policy attention and focus compared to other more prominent risk factors such as tobacco [206]. Other empirical research has found that physical inactivity is reported far less frequently in the news media than tobacco or obesity [207]. Our review results indicate that this lack of attention to physical inactivity 
also seems to apply to assessing public opinion and community attitudes.

Finally, we do note that many interventions targeting physical inactivity are multisectoral in nature; that is, they occur outside the health sector, such as transport interventions, congestion charging or pricing, and urban planning interventions. It is possible that studies reporting on public opinions about such interventions are not published in the public health literature and therefore were not identified in our search strategy.

\section{Strengths and limitations}

The strengths of this review include the use of systematic search terms and processes across four databases along with manual searching of previous and related reviews. While double-screening and reviewing were not used, the first two authors achieved high concordance with $20 \%$ of studies double-screened.

Some limitations of this review include the lack of agreed terminology for terms such as "opinions", "attitudes" and "acceptability", which makes a systematic search for this literature challenging. Similarly, "prevention" can be used in many different contexts. To address this, the reviewers used an inclusive search strategy, which did result in a large number of results that had to be screened. However, some studies may still have been missed. As such this is not a comprehensive systematic review. A full quality assessment of each study was also not performed during the data extraction stage. While some information was gathered (such as sample size and response rates), quality assessment of methods was not possible due to the heterogeneity of studies. This means that methods have been discussed in terms of their general quality. Future research might consider a systematic analysis of study designs and outcomes, though this would be challenging given the significant heterogeneity of methods and other issues that we have outlined in this review.

Another limitation relates to possible publication bias. Only studies published in peer-reviewed journals in the English language were included. This excludes those studies which are not published, including the grey literature, and it also excludes non-English-language publications. Therefore, the patterns of methods in studies in those areas could differ from those reported here. It is important to note that governments and organizations often use market research companies to research how current and hypothetical policies are accepted by the population, but that these are not normally publicly available. Future research could include reviewing the grey literature and explore using access to information laws to obtain the unpublished, market research studies.
Finally, we note that our review was restricted to highincome, democratic countries across Europe, North America and the Asia-Pacific region. Future research could look at replicating this style of review and considering evidence from other countries and regions of the world to compare methods, study designs and areas of study. Furthermore, such research could highlight the effect of different political, social and economic contexts regarding NCD prevention policy and systems change.

\section{Conclusion}

This review has provided an update to previous reviews in this area of research in high-income, democratic countries across Europe, North America and the Asia-Pacific. The majority of studies in this review used quantitative methods, with few using qualitative methods. We also found that tobacco control was the dominant topic investigated in public opinion literature.

These findings demonstrate that opportunities exist to investigate the role of public opinion not only in other prevention topic areas, but also through the use of qualitative and mixed methods to provide more nuanced insights which may facilitate policy implementation of strategies to prevent NCDs. Public opinion and acceptability of prevention is an important feature of effective implementation of preventive strategies; however, there are a variety of ways in which it can be measured and understood. This review has identified some gaps and opportunities for future research which may assist in convincing decision-makers and the broader public of the need to act on NCDs, and to prioritize and implement more upstream preventive strategies and policies.

\section{Supplementary Information}

The online version contains supplementary material available at https://doi. org/10.1186/s12961-022-00829-y.

Additional file 1: PRISMA Checklist.

Additional file 2: Search terms and results.

Additional file 3: Studies included in review.

\section{Acknowledgements}

The authors gratefully acknowledge Ms Bernadette Carr, specialist public health librarian at the University of Sydney, for her support and assistance during the literature search phase of this review.

\section{Authors' contributions}

$\mathrm{EH}, \mathrm{AG}, \mathrm{AB}$ and $\mathrm{BF}$ designed the study. EH prepared and conducted the search strategy. $\mathrm{EH}$ and $\mathrm{KC}$ screened titles and abstracts and full-text articles. $\mathrm{EH}$ and $\mathrm{KC}$ prepared and analysed the results. $\mathrm{EH}, \mathrm{KC}, \mathrm{AG}, \mathrm{EBG}, \mathrm{AB}$ and $\mathrm{BF}$ interpreted the results. $E H, K C, A G, E B G, A B$ and $B F$ drafted and edited the manuscript. All authors read and approved the final manuscript.

\section{Funding}

The Australian Prevention Partnership Centre is supported through the National Health and Medical Research Council (NHMRC) Partnership Centre grant scheme (Grant ID: GNT9100003) with the NHMRC, Australian 
Government Department of Health, ACT Health, Cancer Council Australia, NSW Ministry of Health, Wellbeing SA, Tasmanian Department of Health, and VicHealth. The Australian Prevention Partnership Centre is administered by the Sax Institute. No funders were involved in the collection, analysis or interpretation of data; in the writing of the manuscript; or in the decision to submit the article for publication.

\section{Availability of data and materials}

Relevant data and materials are provided under additional files. The datasets used and/or analysed during the current study are available from the corresponding author on reasonable request.

\section{Declarations}

\section{Competing interests}

The authors declare that they have no competing interests.

\section{Author details}

${ }^{1}$ The Australian Prevention Partnership Centre, Sax Institute, Sydney, Australia. ${ }^{2}$ Prevention Research Collaboration, Sydney School of Public Health, Faculty of Medicine and Health, The University of Sydney, Sydney, Australia. ${ }^{3}$ School of Public Health, Faculty of Medicine, University of Queensland, Brisbane, Australia.

\section{Received: 7 March 2021 Accepted: 15 February 2022}

Published online: 04 March 2022

\section{References}

1. Bennett JE, Kontis V, Mathers CD, Guillot M, Rehm J, Chalkidou K, Kengne AP, Carrillo-Larco RM, Bawah AA, Dain K, et al. NCD Countdown 2030: pathways to achieving Sustainable Development Goal target 3.4. The Lancet. 2020;396:918-34.

2. Roth GA, Abate D, Abate KH, Abay SM, Abbafati C, Abbasi N, Abbastabar H, Abd-Allah F, Abdela J, Abdelalim A, et al. Global, regional, and national age-sex-specific mortality for 282 causes of death in 195 countries and territories, 1980-2017: a systematic analysis for the Global Burden of Disease Study 2017. The Lancet. 2018;392:1736-88.

3. Vos T, Lim SS, Abbafati C, Abbas KM, Abbasi M, Abbasifard M, AbbasiKangevari M, Abbastabar H, Abd-Allah F, Abdelalim A, et al. Global burden of 369 diseases and injuries in 204 countries and territories, 1990-2019: a systematic analysis for the Global Burden of Disease Study 2019. The Lancet. 2020;396:1204-22.

4. Murray CJL, Aravkin AY, Zheng P, Abbafati C, Abbas KM, AbbasiKangevari M, Abd-Allah F, Abdelalim A, Abdollahi M, Abdollahpour I, et al. Global burden of 87 risk factors in 204 countries and territories, 1990-2019: a systematic analysis for the Global Burden of Disease Study 2019. The Lancet. 2020;396:1223-49.

5. Martinez R, Lloyd-Sherlock P, Soliz P, Ebrahim S, Vega E, Ordunez P, McKee M. Trends in premature avertable mortality from non-communicable diseases for 195 countries and territories, 1990-2017: a population-based study. Lancet Glob Health. 2020;8:e511-23.

6. Stokols D. Establishing and maintaining healthy environments: toward a social ecology of health promotion. Am Psychol. 1992;47:6-22.

7. Bonita R, Beaglehole R, Kjellström T, Kjellstrom T. Basic epidemiology. 2nd ed. Geneva: World Health Organization; 2006.

8. Partnership NPH. The language of prevention. Melbourne: National Public Health Partnership; 2006.

9. Honeycutt S, Leeman J, McCarthy WJ, Bastani R, Carter-Edwards L, Clark H, Garney W, Gustat J, Hites L, Nothwehr F, Kegler M. Evaluating policy, systems, and environmental change interventions: lessons learned from CDC's prevention research centers. Prev Chronic Dis. 2015;12:E174.

10. Robles B, Kuo T. Predictors of public support for nutrition-focused policy, systems and environmental change strategies in Los Angeles County, 2013. BMJ Open. 2017;7:e12654.

11. Schmitt CL, Curry L, Boudewyns V, Williams PA, Glasgow L, Van Hersh D, Willett J, Rogers T. Relationships between theoretically derived shortterm outcomes and support for policy among the public and decisionmakers. Prev Chronic Dis. 2018; 15.
12. Goldthorpe J, Epton T, Keyworth C, Calam R, Armitage C. Who is responsible for keeping children healthy? A qualitative exploration of the views of children aged 8-10 years old. BMJ Open. 2019;9:e025245.

13. Sacks G, Swinburn BA, Lawrence MA. A systematic policy approach to changing the food system and physical activity environments to prevent obesity. Austr N Z Health Policy. 2008;5:13.

14. Lang T, Rayner G. Overcoming policy cacophony on obesity: an ecological public health framework for policymakers. Obes Rev. 2007:8:165-81.

15. Adams J, Mytton $O$, White M, Monsivais P. Why are some population interventions for diet and obesity more equitable and effective than others? The role of individual agency. PLOS Med. 2016;13:e1001990.

16. Frieden TR. A framework for public health action: the health impact pyramid. Am J Public Health. 2010;100:590-5.

17. Mozaffarian D, Afshin A, Benowitz NL, Bittner V, Daniels SR, Franch HA, Jacobs DR, Kraus WE, Kris-Etherton PM, Krummel DA, et al. AHA scientific statement population approaches to improve diet, physical activity, and smoking habits a scientific statement from the American heart association. Circulation. 2012. https://doi.org/10.1161/CIR.1160b1013e 318260a318220b.

18. Mozaffarian D, Angell SY, Lang T, Rivera JA. Role of government policy in nutrition-barriers to and opportunities for healthier eating. BMJ. 2018;361:k2426

19. Hoek J. Informed choice and the nanny state: learning from the tobacco industry. Public Health. 2015;129:1038-45.

20. Hyseni L, Atkinson M, Bromley H, Orton L, Lloyd-Williams F, McGill R, Capewell S. The effects of policy actions to improve population dietary patterns and prevent diet-related non-communicable diseases: scoping review. Eur J Clin Nutr. 2017;71:694-711.

21. Lobstein T, Neveux M, Landon J. Costs, equity and acceptability of three policies to prevent obesity: a narrative review to support policy development. Obes Sci Pract. 2020;6:562-83.

22. Bird EL, Ige JO, Pilkington P, Pinto A, Petrokofsky C, Burgess-Allen J. Built and natural environment planning principles for promoting health: an umbrella review. BMC Public Health. 2018; 18:N.PAG-N.PAG.

23. Siegfried N, Parry C. Do alcohol control policies work? An umbrella review and quality assessment of systematic reviews of alcohol control interventions (2006-2017). PLoS ONE. 2019;14:e0214865.

24. Hoffman SJ, Tan C. Overview of systematic reviews on the healthrelated effects of government tobacco control policies. BMC Public Health. 2015;15:744-744.

25. Wright A, Smith KE, Hellowell M. Policy lessons from health taxes: a systematic review of empirical studies. BMC Public Health. 2017;17:583.

26. McDaniel PA, Smith EA, Malone RE. The tobacco endgame: a qualitative review and synthesis. Tob Control. 2016;25:594-604.

27. World Health Organization: Tackling NCDs: 'Best buys' and other recommended interventions for the prevention and control of noncommunicable diseases. pp. 28. Switzerland; 2017:28.

28. World Health Organization. WHO framework convention on tobacco control. Geneva: World Health Organization; 2005.

29. Allen LN, Nicholson BD, Yeung BYT, Goiana-da-Silva F. Implementation of non-communicable disease policies: a geopolitical analysis of 151 countries. Lancet Glob Health. 2020;8:e50-8.

30. Petticrew M, Katikireddi SV, Knai C, Cassidy R, Maani Hessari N, Thomas J, Weishaar H. 'Nothing can be done until everything is done': the use of complexity arguments by food, beverage, alcohol and gambling industries. J Epidemiol Commun Health. 2017;71:1078-83.

31. Greenfield TK, Johnson SP, Giesbrecht N. Public opinion on alcohol policy: a review of US research. Contemp Drug Probl. 2004;31:759-90.

32. Diepeveen S, Ling T, Suhrcke M, Roland M, Marteau TM. Public accept ability of government intervention to change health-related behaviours: a systematic review and narrative synthesis. BMC Public Health. 2013;13:756.

33. Cullerton K, Baker P, Adsett E, Lee A. What do the Australian public think of regulatory nutrition policies? A scoping review. Obes Rev. 2021;22:e13106.

34. Bauman AE, Nutbeam D. Evaluation in a nutshell: a practical guide to the evaluation of health promotion programs. 2nd ed. North Ryde: McGraw-Hill; 2014.

35. Huang TT, Cawley JH, Ashe M, Costa SA, Frerichs LM, Zwicker L, Rivera JA, Levy D, Hammond RA, Lambert EV, Kumanyika SK. Mobilisation 
of public support for policy actions to prevent obesity. Lancet. 2015;385:2422-31.

36. Gollust SE, Barry CL, Niederdeppe J. Americans' opinions about policies to reduce consumption of sugar-sweetened beverages. Prev Med. 2014;63:52-7.

37. Cullerton K, Donnet T, Lee A, Gallegos D. Effective advocacy strategies for influencing government nutrition policy: a conceptual model. Int J Behav Nutr Phys Act. 2018;15:83.

38. Malone RE, Grundy Q, Bero LA. Tobacco industry denormalisation as a tobacco control intervention: a review. Tob Control. 2012;21:162-70.

39. Carroll C, Rick J, Leaviss J, Fishwick D, Booth A. A qualitative evidence synthesis of employees' views of workplace smoking reduction or cessation interventions. BMC Public Health. 2013;13:1095.

40. Thomson G, Wilson N, Collins D, Edwards R. Attitudes to smoke-free outdoor regulations in the USA and Canada: a review of 89 surveys. Tob Control. 2016;25:506-16.

41. Tobin C, Moodie AR, Livingstone C. A review of public opinion towards alcohol controls in Australia. BMC Public Health. 2011;11:58.

42. Moskalewicz J, Wieczorek Ł, Karlsson T, Österberg E. Social support for alcohol policy: literature review. Drugs Educ Prev Policy. 2013;20:361-74.

43. Sikorski C, Kaiser M, Glaesmer H, Schomerus G, Konig HH, Riedel-Heller SG. Attitudes towards and perception of overweight and obesity in the public opinion: a systematic review. Obes Rev. 2011;1:245.

44. Clarke J, Fletcher B, Lancashire E, Pallan M, Adab P. The views of stakeholders on the role of the primary school in preventing childhood obesity: a qualitative systematic review. Obes Rev. 2013;14:975-88.

45. Eykelenboom M, van Stralen MM, Olthof MR, Schoonmade LJ, Steenhuis IHM, Renders CM, Meerpohl J, on behalf of the PENC. Political and public acceptability of a sugar-sweetened beverages tax: a mixed-method systematic review and meta-analysis. Int I Behav Nutr Phys Act. 2019;16:78.

46. Giles EL, Robalino S, McColl E, Sniehotta FF, Adams J. The effectiveness of financial incentives for health behaviour change: systematic review and meta-analysis. PLoS ONE. 2014:9:e90347.

47. Giles EL, Robalino S, Sniehotta FF, Adams J, McColl E. Acceptability of financial incentives for encouraging uptake of healthy behaviours: a critical review using systematic methods. Prev Med. 2015;73:145-58.

48. Hoskins K, Ulrich CM, Shinnick J, Buttenheim AM. Acceptability of financial incentives for health-related behavior change: an updated systematic review. Prev Med. 2019;126:105762.

49. Smith M, Signal L, Edwards R, Hoek J. Children's and parents' opinions on the sport-related food environment: a systematic review. Obes Rev. 2017;18:1018-39.

50. Rowbotham S, Astell-Burt T, Barakat T, Hawe P. 30+ years of media analysis of relevance to chronic disease: a scoping review. BMC Public Health. 2020;20:364.

51. Rowbotham S, McKinnon M, Marks L, Hawe P. Research on media framing of public policies to prevent chronic disease: a narrative synthesis. Soc Sci Med. 2019;237:112428.

52. Whittemore R, Knafl K. The integrative review: updated methodology. J Adv Nurs. 2005;52:546-53.

53. Grant MJ, Booth A. A typology of reviews: an analysis of 14 review types and associated methodologies. Health Info Libr J. 2009:26:91-108.

54. Conduit D, Akbarzadeh S. Pre-election polling and the democratic veneer in a hybrid regime. Democratization. 2020;27:737-57.

55. Covidence. Melbourne, Australia: Veritas Health Innovation Ltd.; 2021.

56. Curry LE, Rogers T, Williams P, Homsi G, Willett J, Schmitt CL. Public attitudes and support for a sugar-sweetened beverage tax in America's Heartland. Health Promot Pract. 2018;19:418-26.

57. Bélanger-Gravel A, Desroches S, Janezic I, Paquette MC, De Wals P. Pattern and correlates of public support for public health interventions to reduce the consumption of sugar-sweetened beverages. Public Health Nutr. 2019;22:3270.

58. Rosenberg M, Pettigrew S, Wood L, Ferguson R, Houghton S. Public support for tobacco control policy extensions in Western Australia: a crosssectional study. BMJ Open. 2012;2:e000784.

59. Trainer E, Gall S, Smith A, Terry K. Public perceptions of the tobaccofree generation in Tasmania: adults and adolescents. Tob Control. 2017:26:458-60
60. Whyte G, Gendall P, Hoek J. Advancing the retail endgame: public perceptions of retail policy interventions. Tob Control. 2014;23:160-6.

61. Gendall P, Hoek J, Maubach N, Edwards R. Public support for more action on smoking. N Z Med J. 2013; 126.

62. Hoek J, Gendall P, Maubach N, Edwards R. Strong public support for plain packaging of tobacco products. Aust N Z J Public Health. 2012;36:405-7.

63. Lykke M, Pisinger C, Glümer C. Ready for a goodbye to tobacco?Assessment of support for endgame strategies on smoking among adults in a Danish regional health survey. Prev Med. 2016;83:5-10.

64. Gallus S, Lugo A, Fernandez E, Gilmore AB, Leon ME, Clancy L, La Vecchia C. Support for a tobacco endgame strategy in 18 European countries. Prev Med. 2014;67:255-8.

65. Dresler C, Wei M, Heck JE, Allwright S, Haglund M, Sanchez S, Kralikova E, Stucker I, Tamang E, Gritz ER, Hashibe M. Attitudes of women from five European countries regarding tobacco control policies. Scand J Public Health. 2013;41:126-33.

66. Cradock AL, Barrett JL, Chriqui JF, Evenson KR, Goins KV, Gustat J, Heinrich KM, Perry CK, Scanze M, Schmid TL, et al. Driven to support: individual- and county-level factors associated with public support for active transportation policies. Am J Health Promot. 2018;32:657-66.

67. Mammen G, Faulkner G, Buliung R, Lay J. Understanding the drive to escort: A cross-sectional analysis examining parental attitudes towards children's school travel and independent mobility. BMC Public Health. 2012; 12 .

68. Kirst M, Shankardass K, Singhal S, Lofters A, Muntaner C, Quiñonez C. Addressing health inequities in Ontario, Canada: what solutions do the public support? BMC Public Health. 2017;17:1-9.

69. Kim KH, Kang E, Yun YH. Public support for health taxes and media regulation of harmful products in South Korea. BMC Public Health. 2019; 19.

70. Moran A, Musicus A, Soo J, Gearhardt AN, Gollust SE, Roberto CA. Believing that certain foods are addictive is associated with support for obesity-related public policies. Prev Med. 2016;90:39-46.

71. Morain S, Mello MM. Survey finds public support for legal interventions directed at health behavior to fight noncommunicable disease. Health Aff. 2013;32:486-96.

72. Mata J, Hertwig R. Public beliefs about obesity relative to other major health risks: representative cross-sectional surveys in the USA, the UK, and Germany. Ann Behav Med. 2018;52:273-86.

73. Ali FRM, Al-Shawaf M, Wang TW, King BA. U.S. Adults' attitudes toward lowering nicotine levels in cigarettes. Am J Prev Med. 2019;57:403-7.

74. Gentzke AS, Glover-Kudon R, Tynan M, Jamal A. Adults' attitudes toward raising the minimum age of sale for tobacco products to 21 years, United States, 2014-2017. Prev Med. 2020;133:106012.

75. Agaku IT, Odani S, Armour BS, King BA. Adults' favorability toward prohibiting flavors in all tobacco products in the United States. Prev Med. 2019; 129.

76. Tynan MA, Wang TW, Marynak KL, Lemos P, Babb SD. Attitudes toward smoke-free casino policies among US adults, 2017. Public Health Rep. 2019;134:234-40.

77. Carlson SA, Guide R, Schmid TL, Moore LV, Barradas DT, Fulton JE. Public support for street-scale urban design practices and policies to increase physical activity. J Phys Act Health. 2011:8(Suppl 1):S125-134.

78. Foltz JL, Harris DM, Blanck HM. Support among U.S. adults for local and state policies to increase fruit and vegetable access. Am J Prev Med. 2012;43:S102-8

79. Agaku IT, Filippidis FT, Vardavas Cl. Effectiveness of text versus pictorial health warning labels and predictors of support for plain packaging of tobacco products within the European union. Eur Addict Res. 2015;21:47-52.

80. Laverty AA, Filippidis FT, Fernandez E, Vardavas Cl. Associations of e-cigarette experimentation with support for tobacco control policies in the European Union, 2012-2014. Tob Induc Dis. 2018;16:1.

81. Lidon-Moyano C, Sampedro-Vida M, Matilla-Santander N, MartinSanchez JC, Gonzalez-Marron A, Bunch K, Martinez-Sanchez JM. Attitudes towards tobacco product regulations and their relationship with the tobacco control policies. Prev Med. 2018;111:67-72.

82. Filippidis FT, Girvalaki C, Mechili EA, Vardavas Cl. Are political views related to smoking and support for tobacco control policies? A survey across 28 European countries. Tob Induc Dis. 2017; 15. 
83. Suggs LS, Mclntyre C. European Union public opinion on policy measures to address childhood overweight and obesity. J Public Health Policy. 2011;32:91-106.

84. Kilian C, Manthey J, Moskalewicz J, Sieroslawski J, Rehm J. How attitudes toward alcohol policies differ across European countries: evidence from the standardized European alcohol survey (seas). Int J Environ Res Public Health. 2019;16:4461.

85. McMillen R, Wilson K, Tanski S, Klein JD, Winickoff JP. Adult attitudes and practices regarding smoking restrictions and child tobacco smoke exposure: 2000 to 2015. Pediatrics. 2018;141:S21-9.

86. McMillen RC, Winickoff JP, Gottlieb MA, Tanski S, Wilson K, Klein JD. Public support for smoke-free section 8 public housing. West J Nurs Res. 2019:41:1170-83.

87. Winickoff JP, McMillen R, Tanski S, Wilson K, Gottlieb M, Crane R. Public support for raising the age of sale for tobacco to 21 in the United States. Tob Control. 2016;25:284-8.

88. Kruger J, Jama A, Kegler M, Marynak K, King B. National and state-specific attitudes toward smoke-free parks among U.S. Adults. Int J Environ Res Public Health. 2016;13:864

89. Kamyab K, Nonnemaker JM, Farrelly MC. Public support for graphic health warning labels in the U.S. Am J Prev Med. 2015;48:89-92.

90. Kruger J, Patel R, Kegler MC, Brener ND, King BA. National and state attitudes of US adults toward tobacco-free school grounds, 2009-2010. Prev Chronic Dis. 2015; 12

91. King BA, Dube SR, Tynan MA. Attitudes toward smoke-free workplaces, restaurants, and bars, casinos, and clubs among U.S. adults: findings from the 2009-2010 national adult tobacco survey. Nicotine Tob Res. 2013;15:1464-70.

92. Callinan S, Room R, Livingston M. Changes in Australian attitudes to alcohol policy: 1995-2010. Drug Alcohol Rev. 2014;33:227-34.

93. Livingston $\mathrm{M}$, Callinan S, Wilkinson C. The impact of high profile restrictions on support for alcohol control policies. Drug Alcohol Rev. 2019;38:399-405.

94. Stanesby O, Rankin G, Callinan S. Experience of harm from others' drinking and support for stricter alcohol policies: analysis of the Australian National Drug Strategy Household Survey. Int J Drug Policy. 2017:45:25-32.

95. Hope A. The ebb and flow of attitudes and policies on alcohol in Ireland 2002-2010. Drug Alcohol Rev. 2014;33:235-41.

96. Seo DC, Macy JT, Torabi MR, Middlestadt SE. The effect of a smoke-free campus policy on college STUDENTS' smoking behaviors and attitudes. Prev Med. 2011:53:347-52

97. Moodie C, MacKintosh AM, Gallopel-Morvan K, Hastings G, Ford A. Adolescents' perceptions of an on-cigarette health warning. Nicotine Tob Res. 2017;19:1232-7.

98. Jaine R, Healey B, Edwards R, Hoek J. How adolescents view the tobacco endgame and tobacco control measures: trends and associations in support among 14-15 year olds. Tob Control. 2015;24:449-54.

99. Sonnenberg J, Bostic C, Halpern-Felsher B. Support for aggressive tobacco control interventions among California adolescents and young adults. J Adolesc Health. 2020;66:506.

100. Palladino R, Hone T, Filippidis FT. Changes in support for bans of illicit drugs, tobacco, and alcohol among adolescents and young adults in Europe, 2008-2014. Int J Public Health. 2018;63:23-31.

101. Ravara SB, Calheiros JM, Aguiar P, Barata LT. Smoking behaviour predicts tobacco control attitudes in a high smoking prevalence hospital: a cross-sectional study in a Portuguese teaching hospital prior to the national smoking ban. BMC Public Health. 2011;11:720

102. Hale N, Murphy AM, Adams JR, Williams CM. Effect of a smoke-free policy on staff attitudes and behaviours within an Australian metropolitan health service: a 3 year cross-sectional study. Aust Health Rev. 2017:41:7-12.

103. Ballor DL, Henson H, MacGuire K. Support for no-smoking policies among residents of public multiunit housing differs by smoking status. J Commun Health. 2013;38:1074-80.

104. Schmidt LM, Reidmohr AA, Helgerson SD, Harwell TS. Secondhand smoke exposure and smoke-free policy support among public housing authority residents in rural and tribal settings. J Commun Health. 2016:41:1116-21.

105. Patel V,Thomson G, Wilson N. Attitudes of business people to proposed smokefree shopping streets. Nicotine Tob Res. 2013;15:287-90.
106. Welch PJ, Dake JA, Price JH, Thompson AJ, Ubokudom SE. State legislators' support for evidence-based obesity reduction policies. Prev Med. 2012:55:427-9.

107. Macy JT, Chassin L, Presson CC. The association between implicit and explicit attitudes toward smoking and support for tobacco control measures. Nicotine Tob Res. 2013;15:291-6.

108. Macy JT, Chassin L, Presson CC. Smoking behaviors and attitudes during adolescence prospectively predict support for tobacco control policies in adulthood. Nicotine Tob Res. 2012;14:871-9.

109. International Tobacco Control (ITC) Policy Evaluation Project. Waterloo: University of Waterloo; 2020.

110. Brown A, Boudreau C, Moodie C, Fong GT, Li GY, McNeill A, Thompson ME, Hassan LM, Hyland A, Thrasher JF, et al. Support for removal of point-of-purchase tobacco advertising and displays: findings from the International Tobacco Control (ITC) Canada survey. Tob Control. 2012;21:555-9.

111. Fong GT, Craig LV, Guignard R, Nagelhout GE, Tait MK, Driezen P, Kennedy R, Boudreau C, Wilquin JL, Deutsch A, Beck F. Evaluating the effectiveness of France's indoor smoke-free law 1 year and 5 years after implementation: findings from the ITC France survey. PLOS ONE. 2013;8:e66692.

112. Edwards R, Wilson N, Peace J, Weerasekera D, Thomson GW, Gifford $H$. Support for a tobacco endgame and increased regulation of the tobacco industry among New Zealand smokers: results from a National Survey. Tob Control. 2013;22:e86-93.

113. Fu M, Castellano Y, Tigova O, Mons U, Agar T, Kyriakos CN, Quah ACK, Fong GT, Trofor AC, Przewozniak K, et al. Correlates of the support for smoke-free policies among smokers: a cross-sectional study in six European countries of the EUREST-PLUS ITC EUROPE SURVEYS. Tob Induc Dis. 2018;16:A17.

114. Hitchman SC, Fong GT, Zanna MP, Hyland A, Bansal-Travers M. Support and correlates of support for banning smoking in cars with children: findings from the ITC Four Country Survey. Eur J Pub Health. 2011:21:360-5.

115. Comans T, Moretto N, Byrnes J. Public preferences for the use of taxation and labelling policy measures to combat obesity in young children in Australia. Int J Environ Res Public Health. 2017;14(3):324.

116. Rissel C, Crane M, Standen C, Wen LM, Ellison R, Greaves S. Public support for bicycling and transport policies in Inner Sydney, Australia: a cross-sectional survey. Aust N Z J Public Health. 2018;42:309-14.

117. Julia C, Mejean C, Vicari F, Peneau S, Hercberg S. Public perception and characteristics related to acceptance of the sugar-sweetened beverage taxation launched in France in 2012. Public Health Nutr. 2015;18:2679-88.

118. Kwon J, Cameron AJ, Hammond D, White CM, Vanderlee L, Bhawra J, Sacks G. A multi-country survey of public support for food policies to promote healthy diets: findings from the International Food Policy Study. BMC Public Health. 2019; 19.

119. Fogarty AS, Chapman S. "Like throwing a bowling ball at a battle ship" audience responses to Australian news stories about alcohol pricing and promotion policies: a qualitative focus group study. PLOS ONE. 2013;8:e62561.

120. Cohn S. Reconceptualising public acceptability: a study of the ways people respond to policies aimed to reduce alcohol consumption. Health (United Kingdom). 2015;20:203-19.

121. Keatley DA, Hardcastle SJ, Carragher N, Chikritzhs TN, Daube M, Lonsdale A, Hagger MS. Attitudes and beliefs towards alcohol minimum pricing in Western Australia. Health Promot Int. 2018;33:400-9.

122. Lonsdale AJ, Hardcastle SJ, Hagger MS. A minimum price per unit of alcohol: a focus group study to investigate public opinion concerning UK government proposals to introduce new price controls to curb alcohol consumption. BMC Public Health. 2012; 12.

123. Somerville C, Marteau TM, Kinmonth AL, Cohn S. Public attitudes towards pricing policies to change health-related behaviours: a UK focus group study. Eur J Pub Health. 2015;25:1058-64.

124. McEvoy CT, Lawton J, Kee F, Young IS, Woodside JV, McBratney J, McKinley MC. Adolescents' views about a proposed rewards intervention to promote healthy food choice in secondary school canteens. Health Educ Res. 2014;29:799-811. 
125. Krukowski CN, Conley KM, Sterling M, Rainville AJ. A qualitative study of adolescent views of sugar-sweetened beverage Taxes, Michigan, 2014. Prev Chronic Dis. 2016; 13.

126. Farrell LC, Warin MJ, Moore VM, Street JM. Socio-economic divergence in public opinions about preventive obesity regulations: is the purpose to 'make some things cheaper, more affordable' or to 'help them get over their own ignorance'? Soc Sci Med. 2016;154:1-8.

127. Haynes-Maslow L, Auvergne L, Mark B, Ammerman A, Weiner BJ. Low-income individuals' perceptions about fruit and vegetable access programs: a qualitative study. J Nutr Educ Behav. 2015;47:317-324.e311.

128. Olsen HM, Brown WJ, Kolbe-Alexander T, Burton NW. Physical activity and sedentary behaviour in a flexible office-based workplace: employee perceptions and priorities for change. Health Promot J Austr. 2018;29:344-52

129. Van Hal G, Tavolacci MP, Stock C, Vriesacker B, Orosova O, Kalina O, Salonna F, Lukacs A, Ladekjaer Larsen E, Ladner J, Jacobs L. European University Students' experiences and attitudes toward campus alcohol policy: a qualitative study. Subst Use Misuse. 2018;53:1539-48.

130. Ladekjaer Larsen E, Smorawski GA, Kragbak KL, Stock C. Students' drinking behavior and perceptions towards introducing alcohol policies on university campus in Denmark: a focus group study. Subst Abuse Treat Prev Policy. 2016;11:17.

131. Fogarty AS, Chapman S. What should be done about policy on alcohol pricing and promotions? Australian experts'views of policy priorities: a qualitative interview study. BMC Public Health. 2013;13:610.

132. Robertson L, Marsh L, Hoek J, McGee R. New Zealand tobacco control experts' views towards policies to reduce tobacco availability. N Z Med J. 2017;130:27-35

133. Signal LN, Watts C, Murphy C, Eyles H, Ni Mhurchu C. Appetite for health-related food taxes: New Zealand stakeholder views. Health Promot Int. 2018:33:791-800.

134. Signal L, Lanumata T, Ni Mhurchu C, Gorton D. Front-of-pack nutrition labelling in New Zealand: an exploration of stakeholder views about research and implementation. Health Promot J Austr. 2012;23:48-51.

135. Davó-Blanes MC, Ortiz-Moncada R, Gil-González D, Álvarez-Dardet C, Lobstein $\mathrm{T}$. The impact of marketing practices and its regulation policies on childhood obesity. Opinions of stakeholders in Spain. Appetite. 2013;62:216-24

136. Jones E, Eyler AA, Nguyen L, Kong J, Brownson RC, Bailey JH. It's all in the lens: differences in views on obesity prevention between advocates and policy makers. Child Obes. 2012;8:243-50.

137. Benowitz-Fredericks C, McQuoid J, Sheon N, Olson S, Ling PM. Voluntary smoke-free measures among Oklahoma nightlife owners: barriers and facilitators. Health Promot Pract. 2018;20:196.

138. Robertson L, Marsh L, Hoek J, McGee R, Egan R. Regulating the sale of tobacco in New Zealand: a qualitative analysis of retailers' views and implications for advocacy. Int J Drug Policy. 2015;26:1222-30.

139. Jaine R, Russell M, Edwards R, Thomson G. New Zealand tobacco retailers' attitudes to selling tobacco, point-of-sale display bans and other tobacco control measures: a qualitative analysis. N Z Med J. 2014;127:53-66

140. Huse $O$, Zorbas C, Jerebine A, Kurzeme A, Blake M, Ferguson M, Palermo C, Peeters A, Orellana L, Brimblecombe J, et al. Recreation centre managers' perceptions of pricing interventions to promote healthy eating. Health Promot Int. 2019;03:03.

141. Signal LN, Jenkin GLS, Barr MB, Smith M, Chambers TJ, Hoek J, Ni Mhurchu C. Prime minister for a day: children's views on junk food marketing and what to do about it. N Z Med J. 2019;132:36-45.

142. Stephens LD, McNaughton SA, Crawford D, Ball K. Nutrition promotion approaches preferred by Australian adolescents attending schools in disadvantaged neighbourhoods: a qualitative study. BMC Pediatrics. 2015; 15.

143. Hoek J, Smith K. A qualitative analysis of low income smokers'responses to tobacco excise tax increases. Int J Drug Policy. 2016;37:82-9.

144. Parnell A, Box E, Biagioni N, Bonevski B, Coffin J, Slevin T, AnwarMcHenry J, Pettigrew S, Anwar-McHenry J. Attitudinal and behavioural responses to increasing tobacco control regulation among high smoking prevalence groups: a qualitative study. Drug Alcohol Rev. 2019;38:92-100.
145. Barry CL, Jarlenski M, Grob R, Schlesinger M, Gollust SE. News media framing of childhood obesity in the United States from 2000 to 2009. Pediatrics. 2011;128:132-45.

146. Ries NM, Rachul C, Caulfield T. Newspaper reporting on legislative and policy interventions to address obesity: United States, Canada, and the United Kingdom. J Public Health Policy. 2011;32:73-90.

147. Kuiper NM, Frantz KE, Cotant M, Babb S, Jordan J, Phelan M. Newspaper coverage of implementation of the Michigan smoke-free law: lessons learned. Health Promot Pract. 2013;14:901-8.

148. Astill Wright L, Golder S, Balkham A, McCambridge J. Understanding public opinion to the introduction of minimum unit pricing in Scotland: a qualitative study using Twitter. BMJ Open. 2019;9:e029690.

149. Feng M, Pierce JP, Szczypka G, Vera L, Emery S. Twitter analysis of California's failed campaign to raise the state's tobacco tax by popular vote in 2012. Tob Control. 2017;26:434-9.

150. Farrell LC, Warin MJ, Moore VM, Street JM. Emotion in obesity discourse: understanding public attitudes towards regulations for obesity prevention. Sociol Health IIIn. 2016;38:543-58.

151. Thomas-Meyer M, Mytton O, Adams J. Public responses to proposals for a tax on sugar-sweetened beverages: a thematic analysis of online reader comments posted on major UK news websites. PLoS ONE. 2017;12:e0186750.

152. Henderson J, House E, Coveney J, Meyer S, Ankeny R, Ward P, Calnan M. Evaluating the use of citizens'juries in food policy: a case study of food regulation. BMC Public Health. 2013; 13.

153. Anaf J, Baum F, Fisher M. A citizens'jury on regulation of McDonald's products and operations in Australia in response to a corporate health impact assessment. Aust N Z J Public Health. 2018;42:133-9.

154. Moretto N, Kendall E, Whitty J, Byrnes J, Hills AP, Gordon L, Turkstra E, Scuffham P, Comans T. Yes, the government should tax soft drinks: findings from a citizens' Jury in Australia. Int J Environ Res Public Health. 2014;11:2456-71.

155. Street JM, Sisnowski J, Tooher R, Farrell LC, Braunack-Mayer AJ. Community perspectives on the use of regulation and law for obesity prevention in children: a citizens' jury. Health Policy. 2017;121:566-73.

156. Street J, Cox H, Lopes E, Motlik J, Hanson L. Supporting youth wellbeing with a focus on eating well and being active: views from an Aboriginal community deliberative forum. Aust N Z J Public Health. 2018;42:127-32.

157. Avery MR, Droste N, Giorgi C, Ferguson A, Martino F, Coomber K, Miller P. Mechanisms of influence: alcohol industry submissions to the inquiry into fetal alcohol spectrum disorders. Drug Alcohol Rev. 2016;35:665-72.

158. Kypri K, Wolfenden L, Hutchesson M, Langley J, Voas R. Public, official, and industry submissions on a Bill to increase the alcohol minimum purchasing age: a critical analysis. Int J Drug Policy. 2014;25:709-16.

159. Russell C, Lawrence M, Cullerton K, Baker P. The political construction of public health nutrition problems: a framing analysis of parliamentary debates on junk-food marketing to children in Australia. Public Health Nutr. 2020;23:2041-52.

160. Katikireddi SV, Hilton S. How did policy actors use mass media to influence the Scottish alcohol minimum unit pricing debate? Comparative analysis of newspapers, evidence submissions and interviews. Drugs Educ Prev Policy. 2015;22:125-34.

161. Fraser T, Kira A. Perspectives of key stakeholders and smokers on a very low nicotine content cigarette-only policy: qualitative study. N Z Med J. 2017;130:36-45.

162. Moshrefzadeh A, Rice W, Pederson A, Okoli CTC. A content analysis of media coverage of the introduction of a smoke-free bylaw in Vancouver parks and beaches. Int J Environ Res Public Health. 2013;10:4444-53.

163. McDaniel PA, Offen N, Yerger V, Forsyth S, Malone RE. "Tired of watching customers walk out the door because of the smoke": a content analysis of media coverage of voluntarily smokefree restaurants and bars. BMC Public Health. 2015; 15.

164. Hilton S, Wood K, Bain J, Patterson C, Duffy S, Semple S. Newsprint Coverage of smoking in cars carrying children: a case study of public and scientific opinion driving the policy debate. BMC Public Health. 2014; 14.

165. Patterson C, Semple S, Wood K, Duffy S, Hilton S. A quantitative content analysis of UK newsprint coverage of proposed legislation to prohibit 
smoking in private vehicles carrying children. BMC Public Health. 2015; 15.

166. Hilton S, Buckton CH, Patterson C, Vittal Katikireddi S, Lloyd-Williams F, Hyseni L, Elliott-Green A, Capewell S. Following in the footsteps of tobacco and alcohol? Stakeholder discourse in UK newspaper coverage of the Soft Drinks Industry Levy. Public Health Nutr. 2019;22:2317-28.

167. Elliott-Green A, Hyseni L, Lloyd-Williams F, Bromley H, Capewell S. Sugar-sweetened beverages coverage in the British media: an analysis of public health advocacy versus pro-industry messaging. BMJ Open. 2016;6:e011295

168. Buckton CH, Patterson C, Hyseni L, Katikireddi SV, Lloyd-Williams F, Elliott-Green A, Capewell S, Hilton S. The palatability of sugar-sweetened beverage taxation: A content analysis of newspaper coverage of the UK sugar debate. PLoS ONE. 2018; 13(12) (no pagination).

169. Niederdeppe J, Gollust SE, Jarlenski MP, Nathanson AM, Barry CL. News coverage of sugar-sweetened beverage taxes: pro- and antitax arguments in public discourse. Am J Public Health. 2013;103:e92-98.

170. Hilton S, Wood K, Patterson C, Katikireddi SV. Implications for alcohol minimum unit pricing advocacy: what can we learn for public health from UK newsprint coverage of key claim-makers in the policy debate? Soc Sci Med. 2014;102:157-64.

171. Patterson C, Katikireddi SV, Wood K, Hilton S. Representations of minimum unit pricing for alcohol in UK newspapers: a case study of a public health policy debate. J Public Health (United Kingdom). 2015;37:40-9.

172. Fogarty AS, Chapman S. Advocates, interest groups and Australian news coverage of alcohol advertising restrictions: content and framing analysis. BMC Public Health. 2012;12:727.

173. Hilton S, Patterson C, Teyhan A. Escalating coverage of obesity in UK newspapers: the evolution and framing of the obesity epidemic from 1996 to 2010. Obesity. 2012;20:1688-95.

174. Kang $Y$, Wang $Y$, Zhang D, Zhou L. The public's opinions on a new school meals policy for childhood obesity prevention in the U.S.: a social media analytics approach. Int J Med Inf. 2017;103:83-8.

175. Freeman B. Tobacco plain packaging legislation: a content analysis of commentary posted on Australian online news. Tob Control. 2011;20:361-6.

176. Grunseit AC, Rowbotham S, Crane M, Indig D, Bauman AE, Wilson A. Nanny or canny? Community perceptions of government intervention for preventive health. Crit Public Health. 2019;29:274-89.

177. Booth E, Halliday V, Cooper RJ. Headteachers' and chairs of governors' perspectives on adolescent obesity and its prevention in English secondary school settings. J Public Health. 2019;12:12.

178. Sharman MJ, Lyth A, Jose KA, Ragaini BS, Blizzard L, Johnston FH, Peterson C, Palmer AJ, Cleland VJ. Acceptability and perceived feasibility of strategies to increase public transport use for physical activity gain - a mixed methods study. Health Promot J Austr. 2019;04:04.

179. Li J, Lovatt M, Eadie D, Dobbie F, Meier P, Holmes J, Hastings G, MacKintosh AM. Public attitudes towards alcohol control policies in Scotland and England: results from a mixed-methods study. Soc Sci Med. 2017:177:177-89.

180. March-Cerdá JC, Danet A, Prieto-Rodríguez MA, Martín-Barato A, LópezDoblas M, Luque-Martín N. Acceptability and impact of measures regulating alcohol consumption among adolescents in Spain: opinions of adolescents, parents, and teachers. J Child Adolesc Subst Abuse. 2013:22:321-39.

181. Schreuders M, Lagerweij NA, Van Den Putte B, Kunst AE. To what extent and why adolescents do or do not support future tobacco contro measures: a multimethod study in the Netherlands. Tob Control. 2018;27:596-9.

182. Payán DD, Lewis LB, Cousineau MR, Nichol MB. Advocacy coalitions involved in California's menu labeling policy debate: exploring coalition structure, policy beliefs, resources, and strategies. Soc Sci Med. 2017;177:78-86.

183. Mah CL, Vanderlinden L, Mamatis D, Ansara DL, Levy J, Swimmer L. Ready for policy? Stakeholder attitudes toward menu labelling in Toronto Canada. Can J Public Health. 2013;104:e229-34.

184. Porter CM, Pelletier DL. Finding common ground: perspectives on community-based childhood obesity prevention. Health Promot Pract. 2012;13:826-34

185. Howse E, Freeman B, Wu JHY, Rooney K. The university should promote health, but not enforce it': Opinions and attitudes about the regulation of sugar-sweetened beverages in a university setting. BMC Public Health. 2017; 18.

186. Duffy SA, Ewing LA, Welsh DE, Flanagan PS, Waltje AH, Breedveld SB, Young EW. Employee attitudes about moving toward a smoke-free campus at a Veterans Affairs hospital. J Addict Nurs. 2013;24:82-90.

187. Nikitas A, Wallgren P, Rexfelt O. The paradox of public acceptance of bike sharing in Gothenburg. Proc Inst Civil Eng. 2016;169:101-13.

188. Aarts MJ, Schuit AJ, van de Goor IA, van Oers HA. Feasibility of multisector policy measures that create activity-friendly environments for children: results of a Delphi study. Implement Sci. 2011;6:128.

189. Brennan LK, Brownson RC, Kelly C, Ivey MK, Leviton LC. Concept mapping: priority community strategies to create changes to support active living. Am J Prev Med. 2012;43:S337-50.

190. Dinour LM, Pole A. Potato chips, cookies, and candy oh my! Public commentary on proposed rules regulating competitive foods. Health Educ Behav. 2017:44:867-75.

191. Glynn CJ, Herbst S, Lindeman M, O'Keefe GJ, Shapiro RY. Public opinion. 3rd ed. Boca Raton: Routledge; 2018.

192. Weisberg H. Total survey error. In: Atkeson LR, Alvarez RM, editors. The Oxford handbook of polling and survey methods. Oxford: Oxford University Press; 2018.

193. The American Association for Public Opinion Research. Standard definitions: final dispositions of case codes and outcome rates for surveys. 9th ed. Washington: The American Association for Public Opinion Research; 2016.

194. Herbst S. History, philosophy, and public opinion research. J Commun. 1993:43:140-5.

195. Krumpal I. Determinants of social desirability bias in sensitive surveys: a literature review. Qual Quant. 2013;47:2025-47.

196. Knox MA, Oddo VM, Walkinshaw LP, Jones-Smith J. Is the public sweet on sugary beverages? Social desirability bias and sweetened beverage taxes. Econ Human Biol. 2020;38:100886.

197. Capacci S, Mazzocchi M, Brasini S. Estimation of unobservable selection effects in on-line surveys through propensity score matching: an application to public acceptance of healthy eating policies. PLOS ONE. 2018;13:e0196020.

198. Ananthapavan J, Sacks G, Brown V, Moodie M, Nguyen P, Veerman L, Mantilla Herrera AM, Lal A, Peeters A, Carter R. Priority-setting for obesity prevention-the Assessing Cost-Effectiveness of obesity prevention policies in Australia (ACE-Obesity Policy) study. PLoS ONE. 2020;15:e0234804.

199. Hunt D. How food companies use social media to influence policy debates: a framework of Australian ultra-processed food industry Twitter data. Public Health Nutr. 2020;24:3124-35.

200. Fabian LEA, Bernat DH, Lenk KM, Shi Q, Forster JL. Smoke-free laws in bars and restaurants: does support among teens and young adults change after a statewide smoke-free law? Public Health Rep. 2011;126:669-76.

201. Suzuki E. Time changes, so do people. Soc Sci Med. 2012;75:452-6.

202. Yang Y, Land KC. Age-period-cohort analysis: new models, methods, and empirical applications. Philadel phia: CRC Press LLC; 2013.

203. Pawson R, Wong G. Public opinion and policy-making. Soc Policy Adm. 2013:47:434-50.

204. World Health Organization. Global action plan on physical activity 2018-2030: more active people for a healthier world. Geneva: World Health Organization; 2018.

205. Ding D. Surveillance of global physical activity: progress, evidence, and future directions. Lancet Glob Health. 2018;6:e1046-7.

206. Bull FC, Bauman AE. Physical inactivity: the "Cinderella" risk factor for noncommunicable disease prevention. J Health Commun. 2011;16:13-26.

207. Chau J, Bonfiglioli C, Chey T, Bauman A. The Cinderella of public health news: physical activity coverage in Australian newspapers, 1986-2006. Aust N Z J Public Health. 2009;33:189-92.

\section{Publisher's Note}

Springer Nature remains neutral with regard to jurisdictional claims in published maps and institutional affiliations. 